\title{
Ensayos de resistencia a compresión Influencia del curado
}

\author{
J. D. WAEMAN \\ Resumen y comentarios P. G.arch DE PAREDES
}

Los ensayos de la resistencia a la compresión de un hormigón, tienen, generalmente, la mayor significación para proyectistas y constructores, por ello estimamos muy interesantes las experiencias que J. D. Pateman publicó en la revista "Concrete" (febrero 1977).

Según Pateman la influencia del curado sobre las propiedades del hormigón endurecido ha sido objeto de numerosas investigaciones; las que él realiza tienen por objeto contribuir al conocimiento de la influencia que las condiciones de curado ejercen sobre los valores que se obtienen al probar la resistencia a la compresión de los cubos de hormigón preparados a pie de obra.

"Es difícil", dice, convencer al personal que realiza la construcción de la importancia que tienen los continuados cambios del ambiente en el cual se encuentran, ordinariamente, los cubos preparados para el ensayo, a lo largo del tiempo que transcurre desde su preparación hasta su rotura.

Acertadamente clasifica en tres grupos las condiciones más generalizadas de curado: Condiciones normalizadas: mantener los cubos, después de extraerlos de sus moldes, sumergidos en agua a temperatura constante y vigilada con frecuencia. Condiciones fuera de norma: mantener los cubos, ya desenmoldados, sumergidos en agua sujeta a las variaciones ambientales y que durante varios meses del año la temperatura es más baja que la indicada en las normas. Otra variante fuera de norma: dejar los cubos, fuera de sus moldes, expuestos al aire libre en lugares donde la temperatura varía diariamente, en límites bastante amplios del día a la noche.

Las condiciones no normalizadas conducen a obtener, en el ensayo de la resistencia, valores menores que los esperados según la dosificación proyectada para el hormigón. De momento esto se atribuye a deficiencias ocurridas en la preparación; se repiten los ensayos, con la consiguiente pérdida de tiempo y, lo que es de mayor gravedad, los valores así obtenidos se utilizan en un cálculo estadístico que determina un incremento de la cantidad de cemento, generalmente innecesaria.

Como en las primeras etapas de las construcciones pequeñas no se dispone de suministro de energía eléctrica, ocurre que se deseca el hormigón acentuándose esta desfavorable circunstancia durante el tiempo que, por lo general, pasa hasta que los cubos llegan al centro de ensayos.

En las investigaciones realizadas por J. D. Pateman se utilizó un cemento tipo "ordinario" de las normas británicas; los áridos no los describe; con estos materiales preparó cinco hormigones dosificados de forma que le permitiese obtener un amplio conjunto de valores en la resistencia a compresión a 28 días; cada mezcla contenía una cantidad de agua tal, que todas alcanzaban un escurrimiento de $50 \mathrm{~mm}$. 
Los ensayos realizados forman dos grupos de finalidad diferente: El objetivo del grupo que designaremos "primero" fue obtener información acerca de la influencia del curado en agua fría. El grupo "segundo" tuvo por finalidad conocer la influencia del curado al aire seco. Con cada uno de los cinco hormigones se procedió así:

\section{Influencia del curado en agua fría}

Se prepararon doce cubos (12). De ellos seis (6) se curaron en condiciones normalizadas (agua a temperatura constante). Cuando alcanzaron 7 días de edad se rompieron tres (3), y al llegar a los 28 días de edad los otros tres (3).

Los otros seis (6) cubos se curaron en un recipiente de hierro galvanizado, que contenía agua. El recipiente estaba tapado con una chapa de madera con un espesor de $25 \mathrm{~mm}$; el fondo y los cosíados del recipiente no fueron protegidos térmicamente; el lugar en el que se situó el recipiente estaba expuesto al sol y al aire. Cuando los seis cubos tenían la edad de 7 días se extrajeron del recipiente. Tres (3) de ellos se rompieron a compresión y los otros tres (3) se trasladaron a un recipiente con agua y situados en condiciones normalizadas (agua a temperatura constante); a los 21 días, cuando los cubos tenían 28 días de edad, se rompieron a compresión. La temperatura del agua en el recipiente sin protección se midió diariamente.

\section{Influencia del curado al aire}

Se prepararon dieciocho (18) cubos. De ellos seis (6) se conservaron en condiciones normalizadas; se rompieron (3) a la édad de 7 días y los otros tres (3) a la de 28 días.

Los doce (12) cubos restantes se curaron al aire. A los 3 días de curado se trasladaron seis (6) a un recipiente con agua en condiciones normales; cuando éstos tenían 7 días de edad se rompieron tres (3) cubos a compresión y los tres (3) que quedaban se rompieron a compresión cuando alcanzaron la edad de 28 días.

Los otros seis cubos (6) continuaron al aire hasta totalizar 6 días de curado. Tres (3) se rompieron a compresión cuando habían alcanzado la edad de 7 días y los otros tres restantes (3) se trasladaron a un recipiente con agua en condiciones normalizadas donde se mantuvieron hasta alcanzar la edad de 28 días, a la cual se rompieron a compresión. Diariamente se midieron la humedad relativa y las temperaturas del aire.

Resultados:

Influencia del curado en agua fría sobre la resistencia

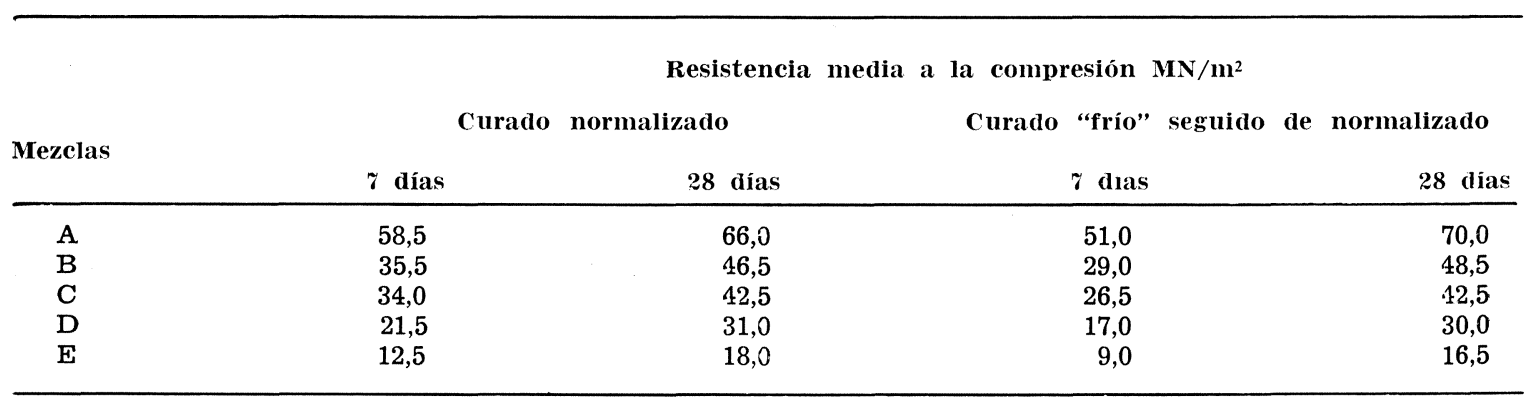




\begin{tabular}{|c|c|c|c|c|c|c|}
\hline \multirow{2}{*}{ Mezclas } & \multicolumn{6}{|c|}{$\begin{array}{l}\text { Resistencia media a la compresión } \mathrm{MN} / \mathrm{m}^{2} \\
3 \text { días al aire } \\
6 \text { dias al aire }\end{array}$} \\
\hline & ¡ días & 28 días & i días & 28 días & $y$ dias & 28 cías \\
\hline$F$ & 54,5 & 66,5 & 47,5 & 62,0 & 42,5 & 61,5 \\
\hline$\%$ normal & & & 87,0 & 93,0 & 78,0 & 92,5 \\
\hline G & 48,0 & 62,0 & 43,5 & 59,5 & 38,5 & 57,0 \\
\hline$\%$ normal & & & 90,5 & 96,0 & 80,0 & 92,0 \\
\hline $\mathrm{H}$ & 47,5 & 59,0 & 43,5 & 56,0 & 40,5 & 55,0 \\
\hline$\%$ normal & & & 91,5 & 95,0 & 85,5 & 93,0 \\
\hline $\mathrm{J}$ & 40,0 & 51,0 & 35.0 & 48,5 & 31,5 & 47,5 \\
\hline$\%$ normal & & & 87,5 & 95,0 & 78,5 & 93,0 \\
\hline $\mathrm{K}$ & 25,5 & 35,5 & 24,0 & 32,5 & 19,0 & 32,0 \\
\hline$\%$ normal & & & 94,0 & 91,5 & 74,5 & 90,0 \\
\hline
\end{tabular}

Los resultados indican que, en los hormigones de mayor resistencia, el curado inicial en agua fría produce mayores resistencias a los 28 días que el curado en condiciones normalizadas continuado. Estos resultados necesitarían una investigación más rigurosa, pero coinciden con los obtenidos por G. D. Plowman.

Las consecuencias de mantener los cubos en aire seco, después de haberlos desenmoldado, se traducen en una permanente pérdida de resistencia a 28 días que alcanza valores entre el $5 \%$ y el $10 \%$ comparada con la alcanzada por los cubos mantenidos en condiciones normalizadas.

El curado en agua fría durante períodos mayores de 7 días tiene poco efecto sobre las resistencias a 28 días; pero si la temperatura es mucho menor que la fijada para el curado normalizado, la resistencia a 7 días resulta alterada y no puede utilizarse para, de ella, deducir la que se alcanzaría a los 28 días.

Es imprescindible utilizar alguna forma de recipiente para que, de acuerdo con la norma británica BS 1881, parte 3 1970, por lo menos los cubos permanezcan 3 días en agua antes de ser sometidos al ensayo.

\section{R E F E R E N C I A S}

S. G. Bergstrom: Curing temperature, age and Strength of concrete. Construction Review, Vol. $27,1954$.

T. WATERs: The effect of allowing concrete to dry out before it has fully cured. Magazine of Concrete Research. Vol. 7, 1955.

J. M. Plowman: Maturity and the streng of concrete. Magazine of Concrete. Research. Vol. 8, 1956.

G. D. Pomeroy: The effect of curing conditions and cubes size on the crus shing streng of concrete. C \& Co. Technical Report. N. 42.470 .1972$.

J. HagGie Patterson \& Associates: Site curing of concrete test cubes in air-the influence on the 28-day comprensive strength. Technical Memorandum N. 3. 1976.

J. HagGie Patterson \& Associates: Site curing of concrete test cubes with unheated water-the influence on the 28-day comprensive strength. Technical Memorandum N. ${ }^{\circ}$ 2. 1975.

BS 1881: Part 3, 1970: Methods of making and curing test specimens. Cluse 4.5.2. Curing test cubes, specimens made in site. 